\title{
Histone Deacetylase Inhibitors As Potential Therapeutic Agents For Various Disorders
}

\author{
KAJAL THAPA, SAVIR KUMAR, ANURAG SHARMA, SANDEEP ARORA \\ AMARJOT KAUR GREWAL AND THAKUR GURJEET SINGH* \\ Chitkara College of Pharmacy, Chitkara University, Rajpura, Punjab, India \\ *Email: gurjeet.singh@chitkara.edu.in
}

Received: June 17, 2017 | Revised: July 21, 2017 I Accepted: Sept. 30, 2017

Published online: Nov. 02, 2017

The Author(s) 2017. This article is published with open access at www.chitkara.edu.in/publications

\begin{abstract}
Epigenetic modification acetylation or deacetylation of histone considered as an important element in various disorders. Histone acetyltransferases (HATs) and histone deacetylases (HDACs) are the enzymes which catalyse the acetylation and deacetylation of histone respectively. It helps in regulating the condensation of chromatin and transcription of genes. Lysine acetylation and deacetylation present on the nucleosomal array of histone is the key factor for gene expression and regulation in a normal working living cell. Modification in histone protein will lead to the development of cancer and can cause various neurodegenerative disorders. To safeguard the cells or histone proteins from these diseases histone deacetylase inhibitors are used. In this review, the main focus is upon the role of histone deacetylases inhibitors in various diseases.
\end{abstract}

Keywords: Epigenetic; Histone; Acetylation; Deacetylation; Lysine; Histone deacetylases inhibitors

\section{INTRODUCTION}

Eukaryotic cell nuclei contain a highly alkaline protein known as histone which helps DNA to attain its helical structure. An octad of four core histones forms a fundamental subunit of chromatin termed as the nucleosome (Kornberg, 1999; Ito et al. 2000). The nucleosome represents a principle protein-nucleic acid relationship of chromatin, (Kornberg, 1999). Four core histones are H3/H4 tetramer and two H2A/H2B dimers (Ito et al. 2000; Strahl, 2000). A chromatin strand consists of 146 base pairs of DNA wrapped around the histone protein give rise to the nucleasomal array (200bp). All these four core histones all contain an N-terminal tail that passes through and around the DNA double

Journal of Pharmaceutical Technology, Research and Management Vol-5, No-2, November 2017 pp. 235-253 
Thapa, K.

Kumar, S. Sharma, A. Arora, S. Grewal, A.K. Thakur, G.S.

helix. This N-terminal of histones is prior to modification during activation of gene transcription and gene expression. The various modifications that can take place are methylation, phosphorylation, and the acetylation. Among this modification, acetylation is widely occurring and understandable modification of histone proteins. Modifications of histones $\mathrm{H} 3$ and $\mathrm{H} 4$ are much more extensively characterized than those of H2A and H2B (Wade, 2001). Acetylation mainly takes place on the amino acid Lysine (Lys). Other post-translational modifications of histone include methylation of Lys and arginine, ubiquitination of lysine phosphorylation of serine and ubiquitination of lysine (Zhang, 2001; Jenuwein, 2001). On histone H3 important positions for acetylation are Lys 9 and 14 and on histone $\mathrm{H} 4$ positions for acetylation are Lys5, 8, 12, 16 (Bjerling et al. 2002). Acetylation of histone is affected by two classes of enzymes-histone acetyltransferases (HATs) and histone deacetylases (HDACs). This acetylation and deacetylation determine the gene expression (Ito et al. 2000; Wade, 2001; Forsberg, 2001)

\section{HISTONE ACETYL TRANSFERASE ACETYLATION}

Acetylation by HATs leads to the uncoiling of the nucleosomal array, which is due to the development of negative charge on histone due to modification process destabilization of the inter-nucleosomal interactions and also due to interaction of phosphate backbone of DNA with histone. Hyperacetylation increased the accessibility of chromatin to transcriptional factor (Cress, 2000).

Generally, hyperacetylation leads to increased transcriptional activity of a gene, whereas hypoacetylation cause repression of gene expression (Ito et al. 2000; Wade, 2001; Forsberg, 2001). A pattern of post-translational modifications (acetylation) makes a "code" which is recognized and translated by nonhistone proteins and multiprotein complexes. These complexes are important aspects for transcription-activation and transcription-repression. HATs are categorised into two big families GNAT (Gcn5-related N-acetyl Transferase) and the MYST (Moz, Ypf2-Sas3, Sas2, Tip60) group and one small family p300/CBP (CREB Binding proteins) family. Nonhistone protein substrate which is targeted by HATs enzyme is collectively termed as FATs (Factor acetyltransferases) including p53,E2F, and GATA1 9 (GATA-binding factor 1) (Roth et al, 2001).

\section{HISTONE DEACETYLASES}

The interaction of histone deacetylases with histone tends to increase electrostatic bond of histones which contains both positively and negatively charged DNA. It leads to more rigid and strong structure of chromatin and 
restrains transcription of gene by controlling the penetrability of transcription factors (Polo and Almouzni, 2005) accompanied by removing neutralizing acetyl groups from the histone Lys tail (Timmermann et al. 2001). HDACs categorized in two major classes. The human class 1 deacetylases contains enzymes similar to yeast transcriptional regulator such as HDACs 1,2,3 and 8 (Joseph et al. 2000). They share homology in their catalytic sites (De Ruijter et al.2003). All class 1 enzymes which are present everywhere in human cell lines and tissues have nuclear location. Another one is human class 2 deacetylase; co-enzymes in this category are similar to HDA1P. Another class which is of class 2 is divided in different sub classes such as class 2a (HDAC4, 7, 5 and 9) and class 2b (HDAC6 and 10) (Glass, 2000). These share similarities in two regions, the one is $\mathrm{C}$-terminal catalytic domain and another one is $\mathrm{N}$-terminal regulatory domain (Grozinger et al. 2001).

Class 2 enzymes have tissue specific expression and free to move across nucleus and cytoplasm. Class 2 also helps in introduction of acetyl group in non-histone proteins. Some other categories are the sirtuins (SIRTI-7) family and maize HD2 (Grozinger et al. 2001; Verdel et al. 1999). Proteins in SIRT group are in much resemblance with yeast SIR2 family of proteins (Glass and Rosenfeld, 2000). HDAC11 which is new member of HDAC family was discovered recently (Verdel et al. 1999).

HDACs enzymes have important role in regulation of basic process of cell cycle growth and programmed cell death (Robertson et al. 2000). HDAC also have important function in cancer growth. It is not only restricted to histone deacetylation (Juan et al. 2000). Down regulation of post translational histone modifications leads to failure of gene transcription. A study showed the loss of acetylated Lys 16 of $\mathrm{H} 4$ is normal even in cancer of human (Fraga et al. 2005).

\section{HISTONE DEACETYLASE INHIBITORS}

The HDAC inhibitors (HDACi) consist of 3 parts: a 'can' part of 'surface recognition domain', which opens gate of active site; a group of zinc binders which chelates zinc ion at the active site and is helpful for catalytic function; and a 'linker' region which bring together the two. The shape of HDAC inhibitors have been refined in various studies of homologue of trichostatin A (TSA) and suberoylanilide hydroxyamic acid (SAHA) (Finnin et al. 1999). The crystal shape of hydroxamate complex which is also known as HDAC8 has been mentioned (Somoza JR et al. 2004). The studies in various labs explored the 3-d structure of catalytic site in HDACs and have also explained about the mechanism of acetylated lysine substrates deacetylation. There is a proper interaction of inhibitors with the active site of zinc on the
Histone

Deacetylase

Inhibitors

As Potential

Therapeutic

Agents For Various

Disorderst

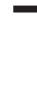


Thapa, K.

Kumar, S.

Sharma, A.

Arora, S.

Grewal, A.K.

Thakur, G.S. base of catalytic pocket. Various HDAC enzymes have different biological activities and HDAC1 and HDAC2 class plays crucial role in transformation of proliferation of cell leading to obtain selective HDAC inhibitors. Tubacin which is a small molecule is created that mainly stops HDAC6 activity and lead to accumulation of acetylated alpha-tubulin, but it doesn't change and stops cell cycle progression and histones acetylation (Haggarty SJ et al. 2003).

HDAC inhibitors discovered till now can be classified into different structural classes which include hyroximates, different cyclic peptides, some of aliphatic acids and also benzamides (Marks PA et al. 2004). TSA, the first natural hydroximate product was discovered which inhibit HDACs. SAHA looks alike TSA structurally and is nanomolar antagonist of HDAC class 1 and 2 (Richon VM et al. 1996). HDAC class 3 is neither inhibited by TSA or SAHA.

CBHA (Carboxycinnamic-m acid Bis-hydroxamide- HDAC inhibitor) which is also known as $\mathrm{M}$-carboxycinnamic acid bishydroxamide is a potent HDAC inhibitor. It shows the structural basis for different derivatives such as LAQ824 and sulfonamide. PXD-101 also inhibit class 1 and 2 HDACs in very small concentrations. The cyclic peptides are structurally very complex group of HDAC inhibitors. They include the natural product which is depsipeptide also known as FK228, another molecule apicidin and sum molecules of chaps group. They all are active in small concentrations. FK228 is a pro drug of red Fk which is an active agent. Other cyclic tetrapeptides which have trifluoroethyl and pentafluoroethyl ketone and also contains zinc binding functional groups are synthesized and are strong HDAC inhibitors (Jose B et al. 2004).

Vorinostat is also structurally similar to TSA (Richon et al. 1998). The different types of aminosuberoyl hydroxamic acids have been established recently which modify proliferation of cells at low concentrations (Belvedere et al. 2007). The first therapeutically FDA approved HDAC inhibitor is vorinostat. Vorinostat is inhibitors of class 1 and class 2 HDAC proteins (Duvic et al. 2007). The Novartis discovered product panobinostat is analogue of hydroxamic acid of CBHA (Marks et al. 2007). Another HDACi, the IF2357 have a hydroxamic acid moiety attached to benzene ring (Leoni et al.2005). Another series of HDACi at small concentrations are aryloxyalkanoic acids which have been recently developed (Marson et al. 2007).

Cyclic peptide is a class of structurally complex group and are HDACi which consist different herbal drugs such as depsipeptide, another name is FK228 and romidepsin, manufactured by Gloucester Pharmaceutical Inc (Jose B et al. 2004). Apicidin and other cyclic hydroxamic acid which contains peptide group are all active at low amount. Depsipeptide also known as FK228 is an active agent and also prodrug for red FK. Cyclic peptides containing 
aliphatic chain to a hydroxamic acid is new HDACi and are active at very minute concentrations such as millimolar (Liu T et al. 2007).

Another class of compounds such as aliphatic acids which contains butyrate, phenylbutyrate and valproic acid, these all are weak antogonist of the HDACs and have action at very low concentrations (Xu W et al. 2005). Drugs like valproic acid and phenyl butyrate have recently shown activity as HDACi. Apart from that they are used in market for non-oncological uses. Pivaloyloxymethyl butyrate also known as AN-9 is manufactured by Titan Pharmaceutical, Inc. It is crucial pro drug for butyric acid (Rasheed WK et al. 2007).

MS-275 which is manufactured by Syndax Pharmaceutical Inc is derivative of benzamide. Another one is MGCD0103 and is dihydobromide salt of aminophenyl benzamide (Gelmon K et al. 2005). M-275 shows more inhibitory action at HDAC1 in comparison to HDAC3 and it have low effect against HDAC6 and very low at HDAC8. Other molecules like SK7041 and SK7068, they only show action against HDAC1 and HDAC2. Another compound name tubacin which is a small molecule, it particularly inhibits the activity of HDAC6 and lead to accumulation of acetylated tubulin. It doesn't stop cell cycle progression (Haggarty SJ et al. 2003).

\section{MECHANISM OF HISTONE DEACYTYLASE INHIBITORS}

HDACi work induce inhibition of cell growth by causing introduction of acetyl group in histones proteins which help in expression of gene, cell growth, cell migration and cell death (Xu et al. 2007). They work by inducing apoptosis by energizing both intrinsic pathway and extrinsic pathway. They mediate tumours cell death due to introduction of apoptosis which result in caspase activation and cell death. Extrinsic pathway start with the attachment of the ligand likely to be as Fas ligand, TNF (Tumour necrosis factor) ligand and TNF related apoptosis inducing ligand also known as TRAIL (Tumour necrosis factor-related apoptosis -inducing ligand) on the surface of cell death receptor (DR) (Johnstone et al. 2002). Intrinsic pathways works through destruction of membrane of mitochondria of cell by stress like radiation, chemical therapies and withdrawing growth factors. HDACi also works by blocking angiogenesis of tumour by stopping HIF which is known as hypoxia inducible factors. Hypoxia regulates expression of gene in VEGF (Vascular endothelial growth factor) by balancing factors such as HIF 1-apha and VHL (Von hippl Lindau) which is tumour suppressor gene. In conditions like hypoxia TSA work by upregulating VHL and p53 and blocking angiogenesis by downregulating VEGF and HIF 1-alpha (Kim et al. 2001). These HDACi shows anti-angiogenic cycle by degrading HSP90 regulating function and exposing of HIF1-alpha
Histone

Deacetylase

Inhibitors

As Potential

Therapeutic

Agents For Various

Disorderst

$\longrightarrow$ 
Thapa, K.

Kumar, S.

Sharma, A.

Arora, S.

Grewal, A.K.

Thakur, G.S.

(Qian et al. 2006). HDACi also cause destruction of DNA with making changes in chromatin conformation at histone acetylation. Another mechanism is production of ROS which is also known as reactive oxygen species which lead to cell death by damage to DNA. HDACi increases production of ROS by downregulation of thioredoxin (Trx) (Marks et al. 2006).

Control over gene expression is primarily kept by HATs and HDAC. The stability between the HATS AND HDACs activity is necessary for normal cellular function. Deregulation as over expression and hypo expression of HDACs/HATs is found to be causative and progressive agents in various cancers and neurodegenerative diseases.

\section{ROLE OF HISTONE DEACETYLASE IN CANCER}

Histone acetylation and deregulation of methylation of DNA are considered as the feature for the development of cancer and further causing deregulation of gene transcriptional factors. Acetylation of Lys 16(K16-H4) and Lys20 (K20-H4) residues are responsible for the relaxed state of chromatin plus the activation of the transcription of genes and has been correlated with genomic functions (Polo, 2005; Vidanes et al. 2005). Deacetylation of the Lys 16, 20 causes are responsible interactions between the histones (negatively charged) and DNA (positively charged) will out turn the compressed structure of chromatin and silence the genes (Johnstone, 2002; Iizuka, 2003). In tumours of GIT, it has been achieved that decrease in acetylation occurs in tumour development as well as in aggregation of tumour and metastasis (Yasui et al. 2003).

There are many ways for HDACs to regulate the expression of genes. In the absence of ligand they form corepressor complexes like N-CoR, SMRT, and $\mathrm{mSin} 3$ (Glass and Rosenfeld, 2000) and mark particular genomic sites by binding to the transcriptional factors, receptors of a nucleus and some specific genes like MBDs (methyl -CpG-binding domain), DNMTs (DNA methyl Transferase), and HMTs (histone methyl Transferase). Binding of these factors will cause the suppression of genes (Jones et al. 1998; Nan et al. 1998).

Translocation of the chromosome is a genetic feature of hematological malignancies as it yields the fusion proteins (RAR-PML, RAR-PLZF) which interacts with the RARE's and initiate the HDAC repressor complex to repress the gene expression by inhibiting the retinoic acid so as to improve the normal functioning of myeloid cells (Lin et al. 2001).

In humans there are different types of HDACs which are responsible for tumourigenesis. Elevation of HDAC1 expression is found in GIT (Choi et al. 2001), colon (Wilson et al. 2006), prostate (Halkidou et al. 2004), colorectal (Zhu et al. 2004) and breast cancer breast (Zhang et al. 2005). The HDAC3 level 
is also elevated in colon cancer (Zhang et al. 2004) and HDAC6 levels are also elevated in the breast (Wilson et al. 2006). The SIRT1 plays a crucial role in cancer as its level is seen to be either increasing or decreasing in cancerous cells. As in lung cancer, prostate cancer and in leukemia the level of SIRT1 is tend to be increasing, whereas in colon cancer there is an attenuation in the level of SIRT1 (Yeung et al. 2004; Kuzmichev et al. 2005; Bradbury et al. 2005; Ozdag et al.2006). HDAC inhibitors promote $\mathrm{p} 21$ expression; $\mathrm{p} 21$ regulates $\mathrm{p} 53$ which is a tumour suppressor. They also inhibit the proliferation of the cell.

Following are some novel inhibitors which can be used in various kind of cancer:

\subsection{1, 3, 4-oxadiazolealanine.}

Pidugu et al prepared the compound (R)-2-Amino-N-((5-phenyl-1, 3, 4-oxadiazol-2-yl) methyl) propanamide (10b) (Pidugu et al. 2016) and considered as a potent HDAC8 inhibitor for the treatment of cancer (Gryder et al. 2012). Bax, $\mathrm{Bcl} 2$, cytochrome $\mathrm{c}$, and PARP are the apoptotic proteins. The $\mathrm{Bcl} 2$ and Bax proteins generates the apoptosis, the levels of $\mathrm{Bcl} 2$ tends to decrease in cancerous cells leading to the formation of homodimers of Bax generating apoptosis in cancerous cells. The HDAC8 inhibitor dose-dependently promotes the expression of $\mathrm{p} 21$ in cancer cells which further inhibits the CDK1 expression. The compound also contributes to the increase in the level of cytochrome $\mathrm{c}$ and breakage of PARP which further inhibits the CDK1 expression by increasing the expression of $\mathrm{p} 21$ in cancer cells. The compound also activates the caspase 3 and 9 in cancerous cells (Pidugu et al. 2017).

In cancer cells, p53 is a protein which suppresses the tumour and induces apoptosis in cancer cells (Chen et al. 2016). Protein p53 also promotes the expression of $\mathrm{p} 21$ which inhibits CDK1/CDK complex and promotes apoptosis (Zhang et al. 2009). There are two apoptotic pathways: extrinsic pathway and intrinsic pathway. The extrinsic pathway is disputed due to the over expression of the $\mathrm{Bcl} 2$ proteins and the intrinsic pathway conclusion is the damage to the mitochondrial membrane which leads to the discharge of cytochrome $\mathrm{c}$ and activation of caspase-3 due to breakage of PARP and fragments of DNA (Naseri et al. 2015).

\subsection{BEBT-908}

The PTEN (tumour suppressor) levels are controlled by PI3K-Akt pathway by altering its transcriptional activity. Akt pathway activates the NF- $\square \mathrm{B}$ transcriptional factor which regulates $\mathrm{PPAR} \beta / \delta$ agonist and $\mathrm{TN} \alpha$ which in turn repress PTEN (Georgescu, 2010).The compound BEBT-908 suppressed
Histone

Deacetylase

Inhibitors

As Potential

Therapeutic

Agents For Various

Disorderst 
Thapa, K.

Kumar, S. Sharma, A. Arora, S. Grewal, A.K. Thakur, G.S.

p-AKT interpretation and considered as a potent PI3K and HDAC inhibitor. BEBT-908 activates mitochondrial-mediated pathways by persuading apoptosis in the cells ( $\mathrm{Li}$ et al. 2017). BEBT-908 also activates G1 phase in cell cycle captured in the cells. HDAC inhibitors typically induce G1 cell cycle arrest through the upregulation of the cyclin-dependent kinase inhibitor p21 (Yazbeck et al. 2015). HDAC inhibitors can also activate the mitochondriamediated apoptotic pathway and regulate the equilibrium between pro- and anti-apoptotic proteins (Rikiishi, 2011; Zhao et al. 2005).

\subsection{Diallyl Trisulfides}

DATS is HDAC inhibitor which alters the HIF-1 $\alpha$ (Hypoxia-inducible factor 1) interpretation in tumour cells. HIF-1 $\alpha$ manages homeostasis via stimulation of the transcriptional factors (Mahon et al. 2001) of the targeted genes such as ANGPTL4, LOXL4, and LOX under hypoxic conditions (Wei et al. 2017). Development of tumour cells initiates the demand of oxygen in the cells and points to angiogenesis (Mazure et al. 2006). Excessive expression of HIF-1 $\alpha$ leads to inflammation and diminish the capability of cells to migrate (Solinas et al. 2009).

The stimulation of the HIF- $1 \alpha$ protein is reduced by DATS by controlling the levels of Trx-1 in the cancer cells. In the case of breast cancers, the levels of the Trx 1 protein are very high. DATS adequately inhibited HIF-1 $\alpha$ to abolish development of breast cancer (Wei et al. 2017). The Trx1 system is highly expressed in breast cancers (Lincoln et al. 2003; Cha et al. 2009) and Trx 1 is considered as the marker for breast cancer (Park et al. 2014).

\section{ROLE OF HISTONE DEACETYLASE INHIBITORS IN NEURODEGENERATIVE DISORDERS.}

\subsection{Parkinson's disease}

In PD brain, dieldrin and paraquat are the neurotoxins which cause acetylation of histone proteins. Not all but $\mathrm{H} 2 \mathrm{AK} 5, \mathrm{H} 3 \mathrm{~K} 9$ and $\mathrm{H} 4 \mathrm{~K} 5$ are implicated in the histone acetulation (Song et al. 2010; Song et al. 2011). P25/Cdk5 caused neuronal death by inhibiting and deregulation of HDAC1. In an in vivo model for ischemia protection HDAC1 act as potentially protective against DNA damage and cultured neuron's neurotoxicity (Kim et al. 2008). Neurotoxicity caused by transcriptional genes (BDNF, GDNE, HSP70, and TH+-IR), $\alpha$-synuclein and MPP + is inhibited by using HDAC inhibitors (Harrison and Dexter, 2013). A study of DAT promoter in the cultured rat N27 cell shows a significant role of valproate in regulating DAT expression via elevating the histone acetylation and proves to be neuroprotective (Green et al. 2017). 


\subsection{Alzheimer's Disease}

In $\mathrm{AD}$ brain, memory destruction, emotional defects and loss of neuron is caused due to the enhanced level of $A \beta$ proteins which further activates the GSK-3 $\beta$. GSK-3 $\beta$ stimulation leads to phosphorylation of tau proteins (Mucke et al. 2012). The HDAC proteins are also indulged in the progression of the $\mathrm{AD}$ by conducting the histone acetylation which alters the gene expression and alleviates the emotional balance and destruction of memory (Stridh, 2010). Inhibitors of HDAC inhibit the hyperphosphorylation of tau achieved by $\mathrm{A} \beta$ protein activation. HDAC inhibitors also allocate the gene expression via activation of proteins like GluR1 (glutamate receptor 1), PSD95 (postsynaptic density protein 95), MAP2 (microtubule-associated tubule 2), etc. (Xu et al. 2011). Various pan-HDAC inhibitors interact with the HDAC proteins that include class I, II and IV (Green et al. 2008).

EVP-0334 enhances both short and long-term memories in mice. Histone deacetylase enzyme unwinds the DNA for effective gene expression.EVP-0334 as histone deacetylase inhibitor, prevents the removal of the acetyl group and maintains the structure of DNA but it loses the compact structure of chromatin which is more open to gene expression (Leventhal et al. 2008). HDACi has both neuroprotective and neurodegenerative properties (Graff et al. 2013). Neuroprotection can be achieved by two ways: activation of transcriptional genes and the other works by maintaining the protein homeostasis comprising various pathways to be involved in controlling protein synthesis to achieve stability and functional properties of the proteasome (Hahnen et al. 2008).

\subsection{Ischemic stroke}

Stroke is caused due to various mechanisms such as excitotoxicity, inflammation, ionic imbalance and oxidative/nitrosative stress (Lo et al. 2003). Activation of microglia and infiltered leukocytes consisting of macrophages cause inflammation in the ischemic brain and leads to degeneration of neurons. Microglia on activation releases the proinflammatory mediators which further cause obstruction to brain and excitotoxicity (Gregersen et al. 2000). HDAC inhibitors such as valproic acid, sodium butyrate, and hydroxamine acid trichostatin decrease the growth of the cell and contribute to the differentiation of the cells. Sodium butyrate and trichostatin exhibits neuroprotective effects (Kim et al. 2007). HDAC inhibitors cause the hyperacetylation of the proteins and change the gene expression. Valproic acid suppresses the inflammation caused by microglia and LPS by suppression of the excretion of TNF- $\alpha$ and preparation of NO. HDAC inhibitors also decrease the p53 levels and levels of proapoptotic proteins (Kim et al., 2007; Chen et al. 2007).
Histone

Deacetylase

Inhibitors

As Potential

Therapeutic

Agents For Various

Disorderst 
Thapa, K.

Kumar, S.

Sharma, A.

Arora, S.

Grewal, A.K.

Thakur, G.S.

\subsection{Huntington's disease}

Huntington disease is a dynamic illness of the brain which causes loss of control in movement, emotional problems, and loss of cognition (Shen et al. 2008). In HD brain the histone enzymes alters the frame of chromatin and regulate the expression of the genes. Enzyme $\mathrm{H} 2 \mathrm{~A}$ is responsible for the acetylation, whereas the $\mathrm{H} 2 \mathrm{~B}$ is responsible for the methylation, the $\mathrm{H} 3$ is responsible for the phosphorylation and the $\mathrm{H} 4$ is responsible for the ubiquitination, and sumoylation of the histone that affects the stability of chromosome, mitosis, and transcription 46 (Tanny et al. 2007). Acetylation and methylation of the lysine 9 and 14 on $\mathrm{H} 3$ lead to transcription and silencing of genes respectively (Nakayama et al. 2001). Phosphorylation is also correlated with the gene transcription 46 (Nowak and Corces et al. 2004).

The networking between HAT and HDAC regulates the acetylation and deacetylation of histone 47. HAT increases the transcription of genes and the HDAC withdraws the acetyl group causing the genes to repress (Marks, 2010). Polyglutamine proteins accumulation in the nucleus will have abnormal interactions with nuclear proteins altering the transcription of genes $(\mathrm{Li}$, 2004). The mutated htt connects the transcriptional factors like CBP, TBP, p53, and sp1 to destroy the functional activity of mitochondria by attenuating the expression of PGC-1 alpha which controls the biogenesis of mitochondria. HDAC inhibitors like SAHA and sodium butyrate increases the acetylation of histone proteins and slowed the evolution of degeneration of neurons. Mutant Htt decreases the levels of transcriptional factors as well as the level of acetylation by segregating the co-activators like CBP and making their aggregates (Sadri-Vakili et al. 2006).

\section{REFERENCES}

[1] Belvedere, S., Witter, D.J., Yan, J., Secrist, J.P., Richon, V. and Miller, T.A., (2007). Aminosuberoyl hydroxamic acids (ASHAs): a potent new class of HDAC inhibitors. Bioorganic \& medicinal chemistry letters, 17(14), 3969-3971. https://doi.org/10.1016/j.bmcl.2007.04.089

[2] Bjerling, P., Silverstein, R.A., Thon, G., Caudy, A., Grewal, S. and Ekwall, K., (2002). Functional divergence between histone deacetylases in fission yeast by distinct cellular localization and in vivo specificity. Molecular and cellular biology, 22(7), 2170-2181. https://doi.org/10.1128/MCB.22.7.2170-2181.2002

[3] Bradbury, C.A., Khanim, F.L., Hayden, R., Bunce, C.M., White, D.A., Drayson, M.T., Craddock, C. and Turner, B.M., (2005). Histone deacetylases in acute myeloid leukaemia show a distinctive pattern of expression that changes selectively in response to deacetylase inhibitors. Leukemia, 19(10), 1751. https://doi.org/10.1038/sj.leu.2403910 
[4] Cha, M.K., Suh, K.H. and Kim, I.H., (2009). Overexpression of peroxiredoxin I and thioredoxin1 in human breast carcinoma. Journal of Experimental \& Clinical Cancer Research, 28(1), 93. https://doi.org/10.1186/1756-9966-28-93

[5] Chen, J., (2016). The cell-cycle arrest and apoptotic functions of p53 in tumour initiation and progression. Cold Spring Harbor perspectives in medicine, doi: 10.1101/cshperspect.a026104. https://doi.org/10.1101/cshperspect.a026104

[6] Chen, P.S., Wang, C.C., Bortner, C.D., Peng, G.S., Wu, X., Pang, H., Lu, R.B., Gean, P.W., Chuang, D.M. and Hong, J.S., 2007. Valproic acid and other histone deacetylase inhibitors induce microglial apoptosis and attenuate lipopolysaccharide-induced dopaminergic neurotoxicity. Neuroscience, 149(1), 203-212. https://doi.org/10.1016/j.neuroscience.2007.06.053

[7] Choi, J.H., Kwon, H.J., Yoon, B.I., Kim, J.H., Han, S.U., Joo, H.J. and Kim, D.Y., (2001). Expression profile of histone deacetylase 1 in gastric cancer tissues. Cancer science, 92(12), 1300-1304. https://doi.org/10.1111/j.1349-7006.2001.tb02153.x

[8] Cress, W.D. and Seto, E., (2000). Histone deacetylases, transcriptional control, and cancer. Journal of cellular physiology, 184(1), 1-16.

https://doi.org/10.1002/(SICI)1097-4652(200007)184:1<1::AIDJCP1>3.0.CO;2-7

[9] De Ruijter, A.J., Van Gennip, A.H., Caron, H.N., Stephan, K.E.M.P. and Van Kuilenburg, A.B., (2003). Histone deacetylases (HDACs): characterization of the classical HDAC family. Biochemical Journal, 370(3), 737-749.

https://doi.org/10.1042/bj20021321

[10] Duvic, M., Talpur, R., Ni, X., Zhang, C., Hazarika, P., Kelly, C., Chiao, J.H., Reilly, J.F., Ricker, J.L., Richon, V.M. and Frankel, S.R., (2007). Phase 2 trial of oral vorinostat (suberooylanilide hydroxamic acid, SAHA) for refractory cutaneous T-cell lymphoma (CTCL). Blood, 109(1), 31-39.

https://doi.org/10.1182/blood-2006-06-025999

[11] Finnin, M.S., Donigian, J.R., Cohen, A. and Richon, V.M., (1999). Structures of a histone deacetylase homologue bound to the TSA and SAHA inhibitors. Nature, 401(6749), 188. https://doi.org/10.1038/43710

[12] Forsberg, E.C. and Bresnick, E.H., (2001). Histone acetylation beyond promoters: long-range acetylation patterns in the chromatin world. Bioessays, 23(9), 820-830. https://doi.org/10.1002/bies.1117

[13] Fraga, M.F., Ballestar,E., Villar-Garea, A., Boix-Chornet, M., Espada, J., Schotta, G., Bonaldi, T., Haydon, C., Ropero, S., Petrie, K. and Iyer, N.G., (2005). Loss of acetylation at Lys16 and trimethylation at Lys20 of histone $\mathrm{H} 4$ is a common hallmark of human cancer. Nature genetics, 37(4), 391-400. https://doi.org/10.1038/ng1531

[14] Fraga, M.F., Ballestar, E., Villar-Garea, A., Boix-Chornet, M., Espada, J., Schotta, G., Bonaldi, T., Haydon, C., Ropero, S., Petrie, K. and Iyer, N.G., (2005). Loss of acetylation at Lys 16 and trimethylation at Lys 20 of histone $\mathrm{H} 4$ is a common hallmark of human cancer. Nature genetics, 37(4), 391-400. https://doi.org/10.1038/ng1531
Histone

Deacetylase

Inhibitors

As Potential

Therapeutic

Agents For Various

Disorderst 
Thapa, K.

Kumar, S.

Sharma, A.

Arora, S.

Grewal, A.K.

Thakur, G.S.
[15] Gelmon, K., Tolcher, A., Carducci, M., Reid, G.K., Li, Z., Kalita, A., Callejas, V., Longstreth, J., Besterman, J.M. and Siu, L.L., (2005). Phase I trials of the oral histone deacetylase (HDAC) inhibitor MGCD0103 given either daily or 3x weekly for 14 days every 3 weeks in patients (pts) with advanced solid tumours. Journal of Clinical Oncology, 23(16), 3147-3147. https://doi.org/10.1200/jco.2005.23.16_suppl.3147

[16] Georgescu, M.M., (2010). PTEN tumour suppressor network in PI3K-Akt pathway control. Genes \& cancer, 1(12), 1170-1177. https://doi.org/10.1177/1947601911407325

[17] Glass, C.K. and Rosenfeld, M.G., (2000). The coregulator exchange in transcriptional functions of nuclear receptors. Genes \& development, 14(2), 121-141.

[18] Glass,C.K.and Rosenfeld,M.G.,2000. The coregulator exchange in transcriptional functions of nuclear receptors. Genes \& development, 14(2), 121-141.

[19] Gräff, J. and Tsai, L.H., (2013). The potential of HDAC inhibitors as cognitive enhancers. Annual review of pharmacology and toxicology, 53, 311-330. https://doi.org/10.1146/annurev-pharmtox-011112-140216

[20] Green, A.L., Zhan, L., Eid, A., Zarbl, H., Guo, G.L. and Richardson, J.R., (2017). Valproate increases dopamine transporter expression through histone acetylation and enhanced promoter binding of Nurr1. Neuropharmacology, 125, 189-196. https://doi.org/10.1016/j.neuropharm.2017.07.020

[21] Green, K.N., Steffan, J.S., Martinez-Coria, H., Sun, X., Schreiber, S.S., Thompson, L.M. and LaFerla, F.M., (2008). Nicotinamide restores cognition in Alzheimer's disease transgenic mice via a mechanism involving sirtuin inhibition and selective reduction of Thr231-phosphotau. Journal of Neuroscience, 28(45), $11500-11510$. https://doi.org/10.1523/JNEUROSCI.3203-08.2008

[22] Gregersen, R.,Lambertsen, K. and Finsen, B., (2000). Microglia and macrophages are the major source of tumour necrosis factor in permanent middle cerebral artery occlusion in mice. Journal of Cerebral Blood Flow \& Metabolism, 20(1), 53-65. https://doi.org/10.1097/00004647-200001000-00009

[23] Grozinger, C.M., Chao, E.D., Blackwell, H.E., Moazed, D. and Schreiber, S.L., (2001). Identification of a class of small molecule inhibitors of the sirtuin family of NAD-dependent deacetylases by phenotypic screening. Journal of Biological Chemistry, 276(42), 38837-38843. https://doi.org/10.1074/jbc.M106779200

[24] Gryder, B.E., Sodji, Q.H. and Oyelere, A.K., (2012). Targeted cancer therapy: giving histone deacetylase inhibitors all they need to succeed. Future medicinal chemistry, 4(4), 505-524. https://doi.org/10.4155/fmc.12.3

[25] Haggarty, S.J., Koeller, K.M., Wong, J.C., Grozinger, C.M. and Schreiber, S.L., (2003). Domain-selective small-molecule inhibitor of histone deacetylase 6 (HDAC6)-mediated tubulin deacetylation. Proceedings of the National Academy of Sciences, 100(8), 4389-4394. https://doi.org/10.1073/pnas.0430973100 
[26] Haggarty, S.J., Koeller, K.M., Wong, J.C., Grozinger, C.M. and Schreiber, S.L., (2003). Domain-selective small-molecule inhibitor of histone deacetylase 6 (HDAC6)-mediated tubulin deacetylation. Proceedings of the National Academy of Sciences, 100(8), 4389-4394. https://doi.org/10.1073/pnas.0430973100

[27] Hahnen, E., Hauke, J., Tränkle, C., Eyüpoglu, I.Y., Wirth, B. and Blümcke, I., (2008). Histone deacetylase inhibitors: possible implications for neurodegenerative disorders. Expert opinion on investigational drugs, 17(2), 169-184. https://doi.org/10.1517/13543784.17.2.169

[28] Halkidou, K., Gaughan, L., Cook, S., Leung, H.Y., Neal, D.E. and Robson, C.N., (2004). Upregulation and nuclear recruitment of HDAC1 in hormone refractory prostate cancer. The Prostate, 59(2), 177-189. https://doi.org/10.1002/pros.20022

[29] Harrison, I.F. and Dexter, D.T., (2013). Epigenetic targeting of histone deacetylase: therapeutic potential in Parkinson's disease? Pharmacology \& therapeutics, 140(1), 34-52. https://doi.org/10.1016/j.pharmthera.2013.05.010

[30] Iizuka, M. and Smith, M.M., (2003). Functional consequences of histone modifications. Current opinion in genetics \& development, 13(2), 154-160. https://doi.org/10.1016/S0959-437X(03)00020-0

[31] Ito,K., Barnes, P.J. and Adcock, I.M., (2000). Glucocorticoid receptor recruitment of histone deacetylase 2 inhibits interleukin-1"ö-induced histone $\mathrm{H} 4$ acetylation on lysines 8 and 12. Molecular and Cellular Biology, 20(18), 6891-6903.

https://doi.org/10.1128/MCB.20.18.6891-6903.2000

[32] Jenuwein, T. and Allis, C.D., (2001). Translating the histone code. Science, 293(5532), 1074-1080. https://doi.org/10.1126/science.1063127

[33] Johnstone, R.W., (2002). Histone-deacetylase inhibitors: novel drugs for the treatment of cancer. Nature reviews. Drug discovery, 1(4), 287.

https://doi.org/10.1038/nrd772

[34] Johnstone, R.W., Ruefli, A.A. and Lowe, S.W., (2002). Apoptosis: a link between cancer genetics and chemotherapy. Cell, 108(2), 153-164.

https://doi.org/10.1016/S0092-8674(02)00625-6

[35] Jones,P.L., Veenstra,J.,Gert,C.,Wade,P.A.,Vermaak,D.,Kass,S.U.,Landsberger, N., Strouboulis, J. and Wolffe, A.P., (1998). Methylated DNA and MeCP2 recruit histone deacetylase to repress transcription. Nature genetics, 19(2).

https://doi.org/10.1038/561

[36] Jose, B., Oniki, Y., Kato, T., Nishino, N., Sumida, Y. and Yoshida, M., (2004). Novel histone deacetylase inhibitors: cyclic tetrapeptide with trifluoromethyl and pentafluoroethyl ketones. Bioorganic \& medicinal chemistry letters, 14(21), 5343-5346. https://doi.org/10.1016/j.bmcl.2004.08.016

[37] Jose, B., Oniki, Y., Kato, T., Nishino, N., Sumida, Y. and Yoshida, M., (2004). Novel histone deacetylase inhibitors: cyclic tetrapeptide with trifluoromethyl and pentafluoroethyl ketones. Bioorganic \& medicinal chemistry letters, 14(21), 5343-5346. https://doi.org/10.1016/j.bmcl.2004.08.016
Histone

Deacetylase

Inhibitors

As Potential

Therapeutic

Agents For Various

Disorderst 
Thapa, K.

Kumar, S.

Sharma, A.

Arora, S.

Grewal, A.K.

Thakur, G.S.
[38] Joseph, J., SIDERIS, M.L., Polly, M.A.K., LORIMER, D.D., MCINTOSH, B. and CLARK, J.M., (2000). Cloning and characterization of a novel human histone deacetylase, HDAC8. Biochemical Journal, 350(1), 199-205.

https://doi.org/10.1042/bj3500199

[39] Juan,L.J., Shia, W.J., Chen, M.H., Yang, W.M., Seto, E., Lin, Y.S. and Wu, C.W., (2000). Histone deacetylases specifically down-regulate p53-dependent gene activation. Journal of Biological Chemistry, 275(27), 20436-20443.

https://doi.org/10.1074/jbc.M000202200

[40] Kim D., Frank C. L., Dobbin M. M., Tsunemoto R. K., Tu W., Peng P. L., Guan J. S., Lee B. H., Moy L. Y., Giusti P., Broodie N., Mazitschek R., Delalle I., Haggarty S. J., Neve R. L., Lu Y., and Tsai L. H. (2008) Deregulation of HDAC1 by $\mathrm{p} 25 / \mathrm{Cdk} 5$ in neurotoxicity. Neuron $\mathbf{6 0}, 803-817$.

https://doi.org/10.1016/j.neuron.2008.10.015

[41] Kim, D., Frank, C.L., Dobbin, M.M., Tsunemoto, R.K., Tu, W., Peng, P.L., Guan, J.S., Lee, B.H., Moy, L.Y., Giusti, P. and Broodie, N., (2008). Deregulation of HDAC 1 by $\mathrm{p} 25 / \mathrm{Cdk} 5$ in neurotoxicity. Neuron, 60(5), 803-817.

https://doi.org/10.1016/j.neuron.2008.10.015

[42] Kim, H.J., Rowe, M., Ren, M., Hong, J.S., Chen, P.S. and Chuang, D.M., (2007). Histone deacetylase inhibitors exhibit anti-inflammatory and neuroprotective effects in a rat permanent ischemic model of stroke: multiple mechanisms of action. Journal of Pharmacology and Experimental Therapeutics, 321(3), 892-901. https://doi.org/10.1124/jpet.107.120188

[43] Kim, M.S., Kwon, H.J., You, M.L., Baek, J.H., Jang, J.E., Sae-Won, L., Moon, E.J., Hae-Sun, K., Seok-Ki, L., Chung, H.Y. and Kim, C.W., (2001). Histone deacetylases induce angiogenesis by negative regulation of tumour suppressor genes. Nature medicine, 7(4), 437. https://doi.org/10.1038/86507

[44] Kornberg, R.D. and Lorch, Y., (1999). Twenty-five years of the nucleosome, fundamental particle of the eukaryote chromosome. Cell, 98(3), 285-294. https://doi.org/10.1016/S0092-8674(00)81958-3

[45] Kuzmichev, A., Margueron, R., Vaquero, A., Preissner, T.S., Scher, M., Kirmizis, A., Ouyang, X., Brockdorff, N., Abate-Shen, C., Farnham, P. and Reinberg, D., (2005). Composition and histone substrates of polycomb repressive group complexes change during cellular differentiation. Proceedings of the National Academy of Sciences of the United States of America, 102(6), 1859-1864. https://doi.org/10.1073/pnas.0409875102

[46] Leoni, F., Fossati, G., Lewis, E.C., Lee, J.K., Porro, G., Pagani, P., Modena, D., Moras, M.L., Pozzi, P., Reznikov, L.L. and Siegmund, B., (2005). The histone deacetylase inhibitor ITF2357 reduces production of pro-inflammatory cytokines in vitro and systemic inflammation in vivo. Molecular medicine, 11(1-12), 1. https://doi.org/10.2119/2006-00005.Dinarello 
[47] Leventhal, L., Tran, A. and Gallager, I., (2008). The histone deacetylase inhibitor EVP-0334 is pro-cognitive in mice.

[48] Li, J., Qian, C., Zhou, Q., Li, J., Li, K. and Yi, P., 2017. BEBT-908: A novel potent PI3K/HDAC inhibitor against diffuse large B-cell lymphoma. Biochemical and Biophysical Research Communications, 491(4), 939-945. https://doi.org/10.1016/j.bbrc.2017.07.139

[49] Li, S.H. and Li, X.J.,(2004). Huntingtin-protein interactions and the pathogenesis of Huntington's disease. TRENDS in Genetics, 20(3), 146-154. https://doi.org/10.1016/j.tig.2004.01.008

[50] Lin, R.J., Sternsdorf, T., Tini, M. and Evans, R.M., (2001). Transcriptional regulation in acute promyelocytic leukemia. Oncogene, 20(49), 7204. https://doi.org/10.1038/sj.onc.1204853

[51] Lincoln, D.T., Ali,E.E., Tonissen,K.F. and Clarke, F.M.,(2003). The thioredoxinthioredoxin reductase system: over-expression in human cancer. Anticancer research, 23(3B), 2425-2433.

[52] Liu, T., Kapustin, G. and Etzkorn, F.A., (2007). Design and synthesis of a potent histone deacetylase inhibitor. Journal of medicinal chemistry, 50(9), 2003-2006. https://doi.org/10.1021/jm061082q

[53] Lo, E.H., Dalkara, T. and Moskowitz, M.A., (2003). Mechanisms, challenges and opportunities in stroke. Nature reviews. Neuroscience, 4(5), 399. https://doi.org/10.1038/nrn1106

[54] Mahon, P.C., Hirota, K. and Semenza, G.L., (2001). FIH-1: a novel protein that interacts with HIF-1 and VHL to mediate repression of HIF-1 transcriptional activity. Genes \& development, 15(20), 2675-2686. https://doi.org/10.1101/gad.924501

[55] Marks, P.A. and Breslow, R., (2007). Dimethyl sulfoxide to vorinostat: development of this histone deacetylase inhibitor as an anticancer drug. Nature biotechnology, 25(1), 84. https://doi.org/10.1038/nbt1272

[56] Marks, P.A., (2006). Thioredoxin in cancer-role of histone deacetylase inhibitors. In Seminars in cancer biology. 16(6), 436-443.

https://doi.org/10.1016/j.semcancer.2006.09.005

[57] Marks, P.A., (2010). The clinical development of histone deacetylase inhibitors as targeted anticancer drugs. Expert opinion on investigational drugs, 19(9), 1049-1066. https://doi.org/10.1517/13543784.2010.510514

[58] Marks,P.A.,Richon, V.M.,Miller,T.and Kelly,W.K.,(2004).Histone deacetylase inhibitors. Advances in cancer research, 91, 137-168.

https://doi.org/10.1016/S0065-230X(04)91004-4

[59] Marson, C.M., Mahadevan, T., Dines, J., Sengmany, S., Morrell, J.M., Alao, J.P., Joel, S.P., Vigushin, D.M. and Coombes, R.C., (2007). Structure-activity relationships of aryloxyalkanoic acid hydroxyamides as potent inhibitors of histone deacetylase. Bioorganic \& medicinal chemistry letters, 17(1), 136-141. https://doi.org/10.1016/j.bmcl.2006.09.085
Histone

Deacetylase

Inhibitors

As Potential

Therapeutic

Agents For Various

Disorderst 
Thapa, K.

Kumar, S.

Sharma, A.

Arora, S.

Grewal, A.K.

Thakur, G.S.
[60] Mazure, N.M., (2006). Hypoxia signalling in cancer and approaches to enforce tumour regression. Nature, 441(7092), 437. https://doi.org/10.1038/nature04871

[61] Mucke, L. and Selkoe, D.J., (2012). Neurotoxicity of amyloid -protein: synaptic and network dysfunction. Cold Spring Harbor perspectives in medicine, 2(7), 1-18. https://doi.org/10.1101/cshperspect.a006338

[62] Nakayama, J.I., Rice, J.C., Strahl, B.D., Allis, C.D. and Grewal, S.I., (2001). Role of histone $\mathrm{H} 3$ lysine 9 methylation in epigenetic control of heterochromatin assembly. Science, 292(5514), 110-113.https://doi.org/10.1126/science.1060118

[63] Nan, X., Ng, H.H., Johnson, C.A. and Laherty, C.D., (1998). Transcriptional repression by the methyl-CpG-binding protein $\mathrm{MeCP} 2$ involves a histone deacetylase complex. Nature, 393(6683), 386. https://doi.org/10.1038/30764

[64] Naseri, M.H., Mahdavi, M., Davoodi, J., Tackallou, S.H., Goudarzvand, M. and Neishabouri, S.H., (2015). Up regulation of Bax and down regulation of Bcl2 during 3-NC mediated apoptosis in human cancer cells. Cancer cell international, 15(1), 55. https://doi.org/10.1186/s12935-015-0204-2

[65] Nowak, S.J. and Corces, V.G., (2004). Phosphorylation of histone H3: a balancing act between chromosome condensation and transcriptional activation. TRENDS in Genetics, 20(4), 214-220. https://doi.org/10.1016/j.tig.2004.02.007

[66] Özda, H., Teschendorff, A.E., Ahmed, A.A., Hyland, S.J., Blenkiron, C., Bobrow, L., Veerakumarasivam, A., Burtt, G., Subkhankulova, T., Arends, M.J. and Collins, V.P.,(2006). Differential expression of selected histone modifier genes in human solid cancers. BMC genomics, 7(1), 90. https://doi.org/10.1186/1471-2164-7-90

[67] Park, B.J., Cha, M.K. and Kim, I.H., (2014). Thioredoxin 1 as a serum marker for breast cancer and its use in combination with CEA or CA15-3 for improving the sensitivity of breast cancer diagnoses. BMC research notes, 7(1), 7. https://doi.org/10.1186/1756-0500-7-7

[68] Pidugu, V.R., Yarla, N.S., Bishayee, A., Kalle, A.M. and Satya, A.K., 2017. Novel histone deacetylase 8-selective inhibitor 1,3, 4-oxadiazole-alanine hybrid induces apoptosis in breast cancer cells. Apoptosis, 1-10. https://doi.org/10.1007/s10495-017-1410-2

[69] Pidugu, V.R., Yarla, N.S., Pedada, S.R., Kalle, A.M. and Satya, A.K., (2016). Design and synthesis of novel HDAC8 inhibitory 2, 5-disubstituted-1, 3, 4-oxadiazoles containing glycine and alanine hybrids with anti cancer activity. Bioorganic \& medicinal chemistry, 24(21), 5611-5617.

https://doi.org/10.1016/j.bmc.2016.09.022

[70] Polo, S.E. and Almouzni, G., (2005). Histone metabolic pathways and chromatin assembly factors as proliferation markers. Cancer letters, 220(1), 1-9 https://doi.org/10.1016/j.canlet.2004.08.024

[71] Qian, D.Z., Kachhap, S.K., Collis, S.J., Verheul, H.M., Carducci, M.A., Atadja, P. and Pili, R., (2006). Class II histone deacetylases are associated with VHLindependent regulation of hypoxia-inducible factor 1. Cancer research, 66(17), 8814-8821. https://doi.org/10.1158/0008-5472.CAN-05-4598 
[72] Rasheed, W.K., Johnstone, R.W. and Prince, H.M., (2007). Histone deacetylase inhibitors in cancer therapy. Expert opinion on investigational drugs, 16(5), 659-678. https://doi.org/10.1517/13543784.16.5.659

[73] Richon, V.M., Emiliani, S., Verdin, E., Webb, Y., Breslow, R., Rifkind, R.A. and Marks, P.A., (1998). A class of hybrid polar inducers of transformed cell differentiation inhibits histone deacetylases. Proceedings of the National Academy of Sciences, 95(6), 3003-3007. https://doi.org/10.1073/pnas.95.6.3003

[74] Richon, V.M., Webb, Y., Merger, R., Sheppard, T., Jursic, B., Ngo, L., Civoli, F., Breslow, R., Rifkind, R.A. and Marks, P.A., (1996). Second generation hybrid polar compounds are potent inducers of transformed cell differentiation. Proceedings of the National Academy of Sciences, 93(12), 5705-5708.

https://doi.org/10.1073/pnas.93.12.5705

[75] Rikiishi, H., (2011). Autophagic and apoptotic effects of HDAC inhibitors on cancer cells. Journal of Biomedicine and Biotechnology, 2011, 1-9.

https://doi.org/10.1155/2011/830260

[76] Robertson, K.D., Ait-Si-Ali, S., Yokochi, T., Wade, P.A., Jones, P.L. and Wolffe, A.P., (2000). DNMT1 forms a complex with Rb, E2F1 and HDAC1 and represses transcription from E2F-responsive promoters. Nature genetics, 25(3), 338.

https://doi.org/10.1038/77124

[77] Roth, S.Y., Denu, J.M. and Allis, C.D., (2001). Histone acetyltransferases. Annual review of biochemistry, 70(1), 81-120.

https://doi.org/10.1146/annurev.biochem.70.1.81

[78] Sadri-Vakili, G. and Cha, J.H.J., (2006). Histone deacetylase inhibitors: a novel therapeutic approach to Huntington's disease (complex mechanism of neuronal death). Current Alzheimer Research, 3(4), 403-408.

https://doi.org/10.2174/156720506778249407

[79] Solinas, G., Germano, G., Mantovani, A. and Allavena, P., (2009). Tumourassociated macrophages (TAM) as major players of the cancer-related inflammation. Journal of leukocyte biology, 86(5), 1065-1073.

https://doi.org/10.1189/jlb.0609385

[80] Somoza, J.R., Skene, R.J., Katz, B.A., Mol, C., Ho, J.D., Jennings, A.J., Luong, C., Arvai, A., Buggy, J.J., Chi, E. and Tang, J., (2004). Structural snapshots of human HDAC8 provide insights into the class I histone deacetylases. Structure, 12(7), 1325-1334. https://doi.org/10.1016/j.str.2004.04.012

[81] Song, C., Kanthasamy, A., Anantharam, V., Sun, F. and Kanthasamy, A.G., (2010). Environmental neurotoxic pesticide increases histone acetylation to promote apoptosis in dopaminergic neuronal cells: relevance to epigenetic mechanisms of neurodegeneration. Molecular pharmacology, 77(4), 621-632.

https://doi.org/10.1124/mol.109.062174
Histone

Deacetylase

Inhibitors

As Potential

Therapeutic

Agents For Various

Disorderst 
Thapa, K.

Kumar, S.

Sharma, A.

Arora, S.

Grewal, A.K.

Thakur, G.S.
[82] Song, C., Kanthasamy, A., Jin, H., Anantharam, V. and Kanthasamy, A.G., (2011). Paraquat induces epigenetic changes by promoting histone acetylation in cell culture models of dopaminergic degeneration. Neurotoxicology, 32(5), 586-595. https://doi.org/10.1016/j.neuro.2011.05.018

[83] Strahl, B.D. and Allis, C.D., (2000). The language of covalent histone modifications. Nature, 403(6765), 41. https://doi.org/10.1038/47412

[84] Stridh, P., (2010). Inheritance of autoimmune neuroinflammation. Institutionen för klinisk neurovetenskap/Department of Clinical Neuroscience.

[85] Tanny, J.C., Erdjument-Bromage, H., Tempst, P. and Allis, C.D., (2007). Ubiquitylation of histone $\mathrm{H} 2 \mathrm{~B}$ controls RNA polymerase II transcription elongation independently of histone $\mathrm{H} 3$ methylation. Genes \& development, 21(7), 835-847. https://doi.org/10.1101/gad.1516207

[86] Timmermann, S., Lehrmann, H., Polesskaya, A. and Harel-Bellan, A., (2001). Histone acetylation and disease. Cellular and Molecular Life Sciences, 58(5), 728-736. https://doi.org/10.1007/PL00000896

[87] Verdel, A. and Khochbin, S., (1999). Identification of a new family of higher eukaryotic histone deacetylases coordinate expression of differentiationdependent chromatin modifiers. Journal of Biological Chemistry, 274(4), 2440-2445. https://doi.org/10.1074/jbc.274.4.2440

[88] Vidanes, G.M., Bonilla, C.Y. and Toczyski, D.P., (2005). Complicated tails: histone modifications and the DNA damage response. Cell, 121(7), 973-976. https://doi.org/10.1016/j.cell.2005.06.013

[89] Wade, P.A., (2001). Transcriptional control at regulatory checkpoints by histone deacetylases: molecular connections between cancer and chromatin. Human molecular genetics, 10(7), 693-698. https://doi.org/10.1093/hmg/10.7.693

[90] Wei, Z., Shan, Y., Tao, L., Liu, Y., Zhu, Z., Liu, Z., Wu, Y., Chen, W., Wang, A. and Lu, Y., (2017). Diallyl Trisulfides, a natural histone deacetylase inhibitor, attenuate HIF1 synthesis and decreases Breast Cancer Metastasis. Molecular Carcinogenesis. https://doi.org/10.1002/mc.22686

[91] Wilson, A.J., Byun, D.S., Popova, N., Murray, L.B., L'Italien, K., Sowa, Y., Arango, D., Velcich, A., Augenlicht, L.H. and Mariadason, J.M., (2006). Histone deacetylase 3 (HDAC3) and other class IHDACs regulate colon cell maturation and p21 expression and are deregulated in human colon cancer. Journal of Biological Chemistry, 281(19), 13548-13558. https://doi.org/10.1074/jbc.M510023200

[92] Xu, K., Dai, X.L., Huang, H.C. and Jiang, Z.F., (2011). Targeting HDACs: a promising therapy for Alzheimer's disease. Oxidative medicine and cellular longevity, 2011. https://doi.org/10.1155/2011/143269

[93] Xu, W.S., Parmigiani, R.B. and Marks, P.A., (2007). Histone deacetylase inhibitors: molecular mechanisms of action. Oncogene, 26(37), 5541.

https://doi.org/10.1038/sj.onc.1210620 
[94] Xu, W.S., Parmigiani, R.B. and Marks, P.A., (2007). Histone deacetylase inhibitors: molecular mechanisms of action. Oncogene, 26(37), 5541. https://doi.org/10.1038/sj.onc.1210620

[95] Yasui, W., Oue, N., Ono, S., Mitani, Y., Ito, R. and Nakayama, H., (2003). Histone acetylation and gastrointestinal carcinogenesis. Annals of the New York Academy of Sciences, 983(1), 220-231. https://doi.org/10.1111/j.1749-6632.2003.tb05977.x

[96] Yazbeck, V.Y. and Grant, S., (2015). Romidepsin for the treatment of nonHodgkin's lymphoma. Expert opinion on investigational drugs, 24(7), 965-979. https://doi.org/10.1517/13543784.2015.1041586

[97] Yeung, F., Hoberg, J.E., Ramsey, C.S., Keller, M.D., Jones, D.R., Frye, R.A. and Mayo, M.W., (2004). Modulation of NFBdependent transcription and cell survival by the SIRT1 deacetylase. The EMBO journal, 23(12), 2369-2380. https://doi.org/10.1038/sj.emboj.7600244

[98] Zhang, M.F., Zhang, Z.Y., Fu, J., Yang, Y.F. and Yun, J.P., (2009). Correlation between expression of $\mathrm{p} 53, \mathrm{p} 21 / \mathrm{WAF} 1$, and MDM2 proteins and their prognostic significance in primary hepatocellular carcinoma. Journal of translational medicine, 7(1), 110. https://doi.org/10.1186/1479-5876-7-110

[99] Zhang, X.D., Gillespie, S.K., Borrow, J.M. and Hersey, P., (2004). The histone deacetylase inhibitor suberic bishydroxamate regulates the expression of multiple apoptotic mediators and induces mitochondria-dependent apoptosis of melanoma cells. Molecular cancer therapeutics, 3(4), 425-435.

[100]Zhang, Y. and Reinberg, D., (2001). Transcription regulation by histone methylation: interplay between different covalent modifications of the core histone tails. Genes \& development, 15(18), 2343-2360. https://doi.org/10.1101/gad .927301

[101]Zhang,Z., Yamashita,H., Toyama, T., Sugiura,H.,Ando, Y., Mita,K., Hamaguchi, M., Hara, Y., Kobayashi, S. and Iwase, H., (2005). Quantitation of HDAC1 mRNA expression in invasive carcinoma of the breast. Breast cancer research and treatment, 94(1), 11-16. https://doi.org/10.1007/s10549-005-6001-1

[102]Zhang, Z., Yamashita, H., Toyama, T., Sugiura, H., Omoto, Y., Ando, Y., Mita, K., Hamaguchi, M., Hayashi, S.I. and Iwase, H., (2004). HDAC6 expression is correlated with better survival in breast cancer. Clinical Cancer Research, 10(20), 6962-6968. https://doi.org/10.1158/1078-0432.CCR-04-0455

[103]Zhao, Y., Tan, J., Zhuang, L., Jiang, X., Liu, E.T. and Yu, Q., (2005). Inhibitors of histone deacetylases target the Rb-E2F1 pathway for apoptosis induction through activation of proapoptotic protein Bim. Proceedings of the National Academy of Sciences of the United States of America, 102(44), 16090-16095. https://doi.org/10.1073/pnas.0505585102

[104]Zhu, P., Martin, E., Mengwasser, J., Schlag, P., Janssen, K.P. and Göttlicher, M., (2004). Induction of HDAC2 expression upon loss of APC in colorectal tumourigenesis. Cancer cell, 5(5), 455-463.

https://doi.org/10.1016/S1535-6108(04)00114-X
Histone

Deacetylase

Inhibitors

As Potential

Therapeutic

Agents For Various

Disorderst

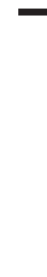

